\title{
PENERAPAN MEDIA ELEKTRONIK PADA PEMBELAJARAN BAHASA ARAB
}

\author{
Luluk Humairo Pimada, ${ }^{1}$ Muhammad Afif Amrulloh ${ }^{2}$ \\ ${ }^{1}$ Institut Agama Islam Negeri Samarinda, Indonesia \\ ${ }^{2}$ Universitas Islam Negeri Raden Intan Lampung, Indonesia \\ ${ }^{1}$ lulukhumairo@samarinda.ac.id \\ 22Afif.amrulloh@radenintan.ac.id
}

\begin{abstract}
Electronic media is currently chosen as one of the solutions to be able to carry out educational activities in the midst of the $19^{\text {th }}$ epidemic sweeping the world; even this application is also carried out for learning Arabic at MTs. level. This study aims to determine the application of electronic media in Arabic language learning, and identify obstacles faced by the students of MTs. Normal Islam Samarinda. The subject of this research is students, the data collection obtained through research instruments in the form of observation, interview, and documentation. Then the analysis of this study using the Miles and Huberman method through the process of data collection, data reduction, and drawing conclusion. The results of this study are the types of electronic media used are smartphones using learning application from social media in the form of whatsapp, google form, and google classroom. Then the obstacles faced internally are students learning styles and varied language skills, and learning motivation. While externally the obstacles come from the lack facilities, the environment that does not support, the cost of spending to support education, and extra time and energy.
\end{abstract}

\section{Keywords: Electronic Media, Teaching and Learning Activities, Arabic Learning}

\section{PENDAHULUAN}

Perangkat pembelajaran terdiri dari peran seorang pengajar, siswa, dan media pembelajaran. Bahakan perangkat pemebelaja-ran adalah alat yang paling utama dalam pelaksanaan kegiatan belajar mengajar diseluruh lembaga pendidikan, dimana perangkat pembelajaran tersebut memiliki hubungan yang berkaitan satu dan yang lainnya. Saat ini peran media pembelajaran sangat diperlukan dengan adanya penetapan kegiatan pembelajaran yang harus dilakukan dengan sistem jarak jauh, berdasarkan ketetapan sosial distancing, yang diberlakukan saat ini. Sehingga dampak tersebut juga berimbas terhadap sistem kegiatan belajar mengajar pada seluruh lembaga pendidikan di seluruh dunia khususnya di Indonesia yang baru memulai menerapkan pembelajaran berbasis teknologi 4.0 .

Dengan demikian peran media pembelajaran menempati posisi yang paling utama diantara perangkat pembelajaran yang lainnya sebagai perantara untuk menyampaikan pesan atau pengetahuan kepada siswa ${ }^{1}$. Namun pemanfaatan media pembelajaran ditengah pandemic covid-19 secara global yang sedang dialami oleh seluruh negeri saat ini dengan cara mengimplementasi-kan media berbasis teknologi ${ }^{2}$ yang diakses secara online sebagai salah satu upaya agar pembelajaran tetap dapat dilakukan ${ }^{3}$, sehingga seorang pengajar terbebas dalam melaksana-kan kewajiban dan siswa mendapatkan hak pendidikan.

Situasi seperti ini memaksa seluruh pihak yang terlibat secara langsung atau tidak langsusng dalam pembelajaran untuk

\footnotetext{
${ }^{1}$ Siti Mahmudah, 'Media Pembelajaran Bahasa Arab', An Nabighoh Jurnal Pendidikan Dan Pembelajaran Bahasa Arab, 20.01 (2018), 129 <https://doi.org/10.32332/an-nabighoh.v20i01.1131>.

${ }^{2}$ Rahmat Iswanto, 'Pembelajaran Bahasa Arab Dengan Pemanfaatan Teknologi', Arabiyatuna: Jurnal Bahasa Arab, $\quad 1.2 \quad$ (2017), 139 <https://doi.org/10.29240/jba.v1i2.286>.

3 Firman and Sari Rahayu, 'Pembelajaran Online Di Tengah Pandemi Covid-19', Indonesian Journal of Educational Science (IJES), 2.2 (2020), 8189 <https://doi.org/10.31605/ijes.v2i2.659>.
} 
membiasakan dengan peralihan sistem pendidikan yang mengarah pada perkembangan teknologi $4.0^{4}$ secara global. Khususnya dalam bidang keislaman acapkali dikesampingkan dengan adanya prespektif yang menyatakan kemerosotan perkembangan pendidikan islam disebabkan tidak adanya reformasi yang terarah dalam perkembangan IPTEK $^{5}$. Maka media pembelajaran berbasis teknologi online dalam pembelajaran bahasa arab saat ini sedang gencar dimanfaatkan dalam penerapan pembelajaran ditengah kebijakan sosial distancing diberlakukan.

Dengan demikian penelitian ini dilakukan untuk mengetahui bagaimana penerapan media elektronik dalam pembelajar-an bahasa Arab, dan mengidentifikasi kendala yang dihadapi oleh siswa terhadap penerapan media elektronik dalam pembelajaran bahasa Arab. Maka dua point penting dalam penelitian ini ditinjau berdasarkan kegiatan belajar mengajar bagi siswa Mts Darussalam Samarinda dengan adanya kebijakan sosial distancing selama masa pandemic covid-19.

Penerapan kebijakan sosial distancing yang berimbas pada dunia pendidikan dialami oleh seluruh jenjang pendidikan dari tingkat dasar hingga perguruan tinggi, sehingga kegiatan belajar mengajar yang menerapkan pembelajaran dengan memanfaatkan askes dunia digitalisasi sebagai wadah untuk memfasilitasi kebutuhan pendidikan pada seluruh bidang keilmuan, sebagai bentuk implementasi dari perkembangan IPTEK. Sebagaimana yang telah dilakukan oleh beberapa lembaga pendidikan di Indonesia berdasarkan beberapa kajian penelitian.

Penerapan teknologi berbasis online pada tingkat sekolah dasar ditengah pandemic covid-19 mendapatkan banyak kendala yang

4 Nanang Budianto and Khuri'In Ratnasari, 'Memperkuar Pendidikan Islam Di Era (Four Point Zero/4.0)', Falasifah: Jurnal Studi Keislaman, 11.1 (2020), $62-78$ <https://doi.org/https://doi.org/10.36835/falasifa.v11i1. $277>$.

5 S Priyatmoko, 'Memperkuat Eksistensi Pendidikan Islam Di Era 4.0', Ta'lim: Jurnal Studi Pendidikan Islam, 1.2 (2018), 221-39 $<$ https://doi.org/https://doi.org/10.29062/ta'lim.v1i2.94 $8>$. harus dihadapi dalam pelaksanaan kegiatan belajar mengajar dirumah masing-masing ${ }^{6}$. Berbeda halnya dengan penerapan yang diberlangsung pada jenjang perguruan tinggi yang mendapatkan tangpapan yang baik dikalangan mahasiswa dengan diberlakukannya pembelajaran melalui sistem daring ${ }^{7}$. Akan tetapi fonomena yang dialami oleh dunia pendidikan tidak hanya sebatas pendidikan yang dilaksanakan di kalangan lembaga pendidikan saja, melainkan keluarga yang memiliki peran penting dalam keberlangsung-an proses pendidikan ditengah wabah covid- $19^{8}$ yang dirasakan oleh seluruh makhluk dimuka bumi ini.

Kegiatan pendidikan di tengah wabah covid-19 ini memiliki banyak kendala yang menjadi hambatan dalam kelancaran pelaksanaan pembelajaran baik yang dirasakan oleh para pengajar, siswa, hingga orang tua siswa. Beberapa kendala yang dihadapi diantaranya adalah ketersedian sarana prasarana yang kurang memadai bagi sebagain kelompok, seperti halnya kendala perekonomi $^{9}$ dalam kehidupan masysrakat untuk bertahan hidup, sehingga berdampak pada perlengkapan sarana pembelajaran yang harus diakses melalui koneksi jaringan internet $^{10}$ sebagai bentuk pembelajaran

${ }^{6}$ Agus Purwanto and others, 'Studi Eksploratif Dampak Pandemi COVID-19 Terhadap Proses Pembelajaran Online Di Sekolah Dasar', Journal of Education, Psychology, and Counseling, 2.1 (2020), 112

<https://www.researchgate.net/publication/340661871_ Studi_Eksploratif_Dampak_Pandemi_COVID-

19_Terhadap_Proses_Pembelajaran_Online_di_Sekola h_Dasar>.

${ }^{7}$ Dian Ratu Ayu Uswatun Khasanah, Hascaryo Pramudibyanto, and Barokah Widuroyekti, 'Pendidikan Dalam Masa Pandemi Covid-19', Jurnal Sinestesia, 10.1 (2020), 41-48.

Subarto, 'Momentum Keluarga Mengembangkan Kemampuan Belajar Peserta Didik Di Tengah Wabah Pandemi Covid-19', Adalah: Buletin Hukum Dan Keadilan, 4.1 (2020), 13-18 <https://doi.org/10.15408/adalah.v4i1.15383>.

9 Fauzan, 'Menjaga Keragaman Ekonomi

Rakyat Di Tengah Pandemi Covid-19', Pendidikan Multikultural, $\quad 4.1 \quad$ (2020), $112-23$ <https://doi.org/http://dx.doi.org/10.33474/multikultura 1.v4i1.6719>.

${ }^{10}$ Wahyu Aji Fatma Dewi, 'Dampak Covid-19 Terhadap Implementasi Pembelajaran Daring MI', 
daring, sebagaimana sistem pembelajaran yang saat ini diterapkan oleh seluruh lembaga pendidikan secara global.

\section{METODE PENELITIAN}

Dalam kajian penelitian ini, peneliti menggunakan metode penelitian berupa deskriptif kuantitatif, untuk mengungkap dan mengidentifikasi penerapan pembelajaran bahasa Arab pada siswa tingat MTs dengan adanya implementasi media teknologi pada pelaksanaaan kegiatan belajar mengajar yang sedang berlangsung saat ini, khususnya sejak berlangsungnya kebijakan WFH akibat wabah covid-19 di Indonesia. Selain itu untuk mengetahui kendala yang dialami oleh siswa tentang penerapan media elektronik dalm pembelajaran bahasa Arab.

Adapun subjek penelitian ini adalah siswa MTs di Normal Islam Samarinda, Pengumpulan data dalam penelitian ini melalui instrumen penelitian yang digunakan berupa observasi, wawancara, dan dokumentasi. Sedang analisis penelitian yang digunakan dengan metode Miles Dan Huberman $^{11}$ melalui proses pengumpulan data, reduksi data, penyajian data, dan penarikan kesimpulan.

\section{PEMBAHASAN DAN HASIL PENELITIAN}

Penelitian ini dilakukan untuk mengidentifikasi dua point penting yakni pertama: mengetahui penerapan pembelajaran bahasa Arab memalui media elektronik pada siswa MTs di wilayah Samarinda, dan kedua: kendala yang dialami oleh siswa saat penerapan media elektronik diberkalukan dalam kegiatan belajar mengajar. Adapun penjelasan terkait kedua point penting ini adalah sebagai berikut:

Edukatif: Jurnal Ilmu Pendidikan, 2.1 (2020), 55-61 <https://doi.org/https://doi.org/10.31004/edukatif.v2i1. 89>.

11 Milles dan Huberman, Analisis Data Kualitatif, (Jakarta: Universitas Indonesia Press, 1992), 16.

\section{Penerapan Media Elektronik pada Pembelajaran Bahasa Arab bagi Siswa MTs Normal Islam Samarinda}

Penerapan media elektronik dalam proses pembelajaran sudah lama digunakan guna memudahkan pengajar dalam menyampaikan informasi dan ilmu pengetahu-an kepada siswa, hal ini dipilih dengan alasan yang sangat mendasar yakni media elektornik lebih banyak diminati sejak teknologi 4.0 sudah mulai dikembangkan dalam dunia pendidikan untuk seluruh bidang ilmu pengetahuan sebagai bentuk implementasi IPTEK.

Perkembangan teknologi berbasis 4.0 memberi dampak yang sangat besar dalam dunia pendidikan keislaman ${ }^{12}$ tidak terlepas pula pada pembelajaran bahasa Arab yang senantiasa mengalami proses perkembangan untuk menyesuaikan kebutuhan pendidikan. Sebagaimana penerapan media elektronik dalam pembelajaran Bahasa Arab telah diterapkan dalam berbagai macam bentuk model pembelajaran yang memanfaatkan pengembangan teknologi seperti pembelajaran melalui multimedia pembelajaran ${ }^{13}$, pengembangan modul pembelajaran Bahasa Arab berbasis elektronik $^{14}$, hingga pembuatan soal-soal berbasis elektronik ${ }^{15}$ untuk memudahkan siswa melatih kemampuan bahasa mereka.

Saat ini media elektronik dimanfaatkan oleh seluruh kalangan yang terlibat secara

12 Cahya Edi Setyawan and Khairul Anwar, 'Peran Bahasa Arab Dalam Pendidikan Islam Sebagai Urgensitas Mengahadapi Revolusi Industri 4.0', Jurnal Lahjah Arabiah, 1.1 (2020), 14-29.

13 Ida Suryani Wijaya and Luluk Humairo Pimada, 'Ta'lim Al-Imla' Bi Al-Wasait AlMuta'addodah Li Tarqiyati Maharah Al-Kitabah Fi AlLughah Al-'Arabiyah', Jurnal Al Bayan: Jurnal Jurusan Pendidikan Bahasa Arab, 11.2 (2019), 194$213<$ https://doi.org/10.24042/albayan.v>.

14 Koderi, 'Pengembangan Modul Elektronik Berbasis SAVI Untuk Pembelajaran Bahasa Arab', Jurnal Teknologi Pendidikan, 19.3 (2017), 206-23 <https://doi.org/https://doi.org/10.21009/JTP1903.4>.

15 Diah Rahmawati, 'PEMANFAATAN WORDERSHARE QUIZ CREATOR DALAM PEMBUATAN SOAL-SOAL BAHASA ARAB Arabi : Journal of Arabic Studies', Journal of Arabic Studies, $\quad 2.1 \quad$ (2017), $\quad 37-46$ <https://doi.org/http://dx.doi.org/10.24865/ajas.v2i1.24 $>$. 
langsung terhadap pelaksanaan kegiatan pendidikan, khususnya dalam pembelajaran Bahasa Arab yang dilaksanakan oleh MTs Normal Islam yang terletak di pusat ibu kota Samarinda propinsi Kalimantan Timur ${ }^{16}$, maka faktor wilayah mendukung disertai oleh jumlah siswa yang mayoritas berdomisili di wilayah perkotaan media elektronik merupakan salah satu solusi yang dipilih untuk tetap melaksanakan kegiatan belajar mengajar selama kebijakan Sosial Distancing diberlakukan.

Bentuk penerapan media elektronik pada pembelajaran Bahasa Arab amat beragam, namun secara mayoritas baik pengajar maupun siswa memilih dan bersepakat menggunakan media elektronik yang mudah untuk diakses dan digunakan, hal ini berdasarkan hasil observasi dengan menggunkan lembar observasi via google form serta wawancara yang dilakukan peneliti via telepon, video call, serta record voiec. Hal ini dipilih dengan adanya kebijakan WFH selama masa wabah covid-19 melanda diberbagai wilayah Indonesia.

Adapun hasil yang diperoleh dari responden seluruhnya menyatakan bahwa sejak sekolah memberikan keputusan untuk mengikuti kebijakan dan Surat Edaran Mendikbud No. 4 Tahun 2020 bahwa pelaksanaan seluruh kegiatan belajar mengajar harus dilakukan dari rumah masingmasing, namun dengan ketetapan bahwa jam pelaksaan kegiatan belajar mengajar tetap dilaksanakan sebagaimana kegiatan belajar mengajar di sekolah, dimulai dari pukul 07.30 hingga pukul 15.00 WITA. Sedangkan khusus bidang studi Bahasa Arab dilaksanakan setiap hari Selasa untuk siswa kelas VII, hari rabu untuk siswa kelas VIII, dan hari kamis untuk siswa kelas IX dengan durasi waktu pembelajaran 3 JPL dalam satu minggu.

Bentuk media elektronik sebagai salah satu bentuk teknologi informatika ${ }^{17}$ yang

https://referensi.data.kemdikbud.go.id/tabs.php?npsn=3 $\underline{0410095}$, di akses pada 04 Mei 2020, pukul: 13.00 WITA.

17 Umar Fauzan and Luluk Humairo Pimada, 'ICT-Based Teaching of English at Madrasah Aliyah in Kalimantan', TARBIYA: Journal of Education in dapat dimanfaatkan untuk melaksanakan pembe-lajaran melalui beberapa bentuk aplikasi google classroom, zoom, google form, grup whatsapp, line, facebook, bahkan instagram. Sedangkan pelaksanaan pembelajaran Bahasa Arab selama kebijakan WFH pengajar dan siswa memanfaatkan media elektronik yang mereka miliki di rumah, peneliti menyimpulakan pengunaan media elektronik yang paling sering dimanfaatkan berdasarkan klasisfikasi jawaban siswa yang harus dipilih melalui google form dengan hasil yang diperoleh sebagaimana hasil dari diagram dibawah ini.

\section{Penggunaan Media Elektronik Dalam Pembelajaran Bahasa Arab Di MTs Normal Islam Samarinda}

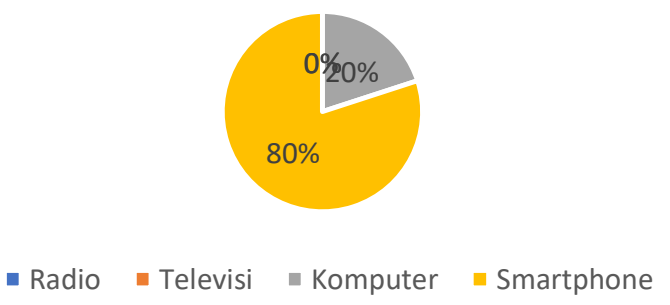

Dengan demikian tidak dapat dipungkiri bahwa perkembangan IPTEK di era teknologi 4.0 memiliki pengaruh yang sangat besar terhadap pemilihan jenis media elektronik saat ini ${ }^{18}$. Terbukti dengan adanya kebutuhan hidup masyarakat yang dapat dipenuhi oleh teknologi secara efektif dan efesien, maka sedikit demi sedikit teknologi yang dianggap kurang modern jarang digunakan.

Pembelajaran Bahasa Arab di tingkat MTs pada lembaga-lembaga pendidikan islam formal pada umumnya menekankan pada pencapaian keterampilan kebahasaan hal ini terlihat dari bentuk latihan-latihan yang ada pada buku-buku pembelajaran yang digunakan, hal ini diperkuat dengan jawaban yang diberikan oleh responden berdasarkan

\footnotetext{
Muslim Society, $5.2 \quad$ (2018), 193-211 <https://doi.org/10.15408/tjems.v5i2.10414>.

18 Rully Rina Widyasari and M. Mukhibat, 'Repisisi Dan Reaktualisasi Pendidikan Madrasah Dalam Memperkuat Eksistensi Pendidikan Di Era 4.0', Edukasia: Jurnal Pendidikan Dan Pembelajaran, 1.1 (2020), 1-13.
} 
tugas-tugas yang diberikan selama pembelajar-an berbasis WFH.

Bentuk Latihan atau Tugas Pembelajaran Bahasa Arab

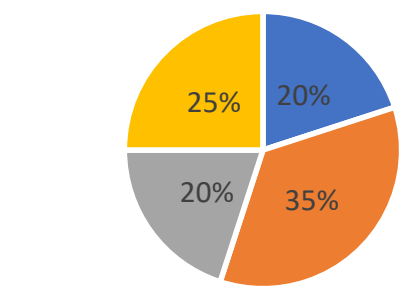

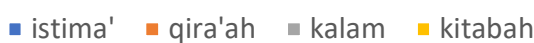

Berdasarkan mayoritas jawaban yang diberikan oleh respodent maka selama pembelajaran bahasa Arab yang dilakukan dirumah mereka banyak diberikan latihanlatihan tentang keterampilan kebahasaan, bahkan berdasarkan klasifikasi jawaban yang diberikan latihan yang paling dominan diberikan adalah qira'ah dan kitabah. Kedua keterampilan bahasa Arab berupa qira'ah dan kitabah banyak diberikan oleh sebagian besar para pengajar bahasa Arab di tingkat MTs hal ini selaras dengan pendapat yang menyatakan bahwa modal utama agar dapat menghasilkan pembelajaran Bahasa Arab yang baik dapat dilihat dari kemampuan membaca dan menulis siswa ${ }^{19}$, dengan demikian integritas bidang studi keislaman terhadap bidang studi lainnya dalam lembaga-lembaga pendidikan Islam akan selalu mendominasi, khususnya terhadap pembelajaran Bahasa Arab.

Kemudian untuk memudahkan penerapan media elektronik saat pembelajaran bahasa Arab dilaksanakan maka pengajara dan siswa di MTs Normal Islam menggunakan berbagai bentuk aplikasi yang dapat diakses melalui komputer, handphone, smartphone. Berdasarkan jawaban yang dijelaskan oleh responden aplikasi yang dipilih dapat dilihat melalui diagram dibawah ini.

${ }^{19}$ Luluk Humairo Pimada, Imam Muttaqin, and Wildana Wargadinata, 'Arabic Learning Though the Ability of Reading and Writing Al-Qur'an in Tsanawiyah Madrasah Level Students in East Kalimantan', Taqdir: Jurnal Pendidikan Bahasa Dan $\begin{array}{lll}\text { Kebahasaan, } & 5.2 \quad \text { (2019), } & 1-17\end{array}$ <https://doi.org/https://doi.org/10.19109/taqdir.v5i2>.
Aplikasi Pembelajaran Bahasa Arab melalui Media Elektronik

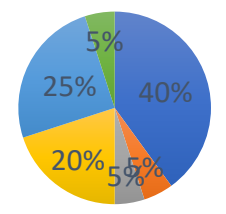

$$
\begin{aligned}
& \text { whatsapp } \quad \text { line } \\
& \text { google classrom } \square \text { google form } \quad \text { zoom }
\end{aligned}
$$

Berdasarkan diagram diatas aplikasi yang paling sering digunakan adalah whatsapp, google form, dan google classroom. Pemilihan tiga bentuk aplikasi ini dimanfaatkan oleh pengajar dan siswa dengan alasan bahwa tiga bentuk aplikasi inilah yang paling mudah untuk diimplementasikan dalam pembelajaran Bahasa Arab saat ini dengan adanya kebeijakan sosial distancing.

Akan tetapi dalam setiap pelaksanaan pembelajaran secara keseluruhan pasti terdapat berbagai macam bentuk permasalahan yang timbul sehingga menjadi kendala yang menghambat pelaksanaan kegiatan pembelajaran, dalam hal ini khususnya pembelajaran Bahasa Arab yang dilaksanakan dengan sistem WFH.

\section{Hambatan pada Implementasi Penerapan Media Elektronik Saat Pembelajaran Bahasa Arab bagi Siswa MTs Normal Islam di Samarinda}

Problemetika dalam penerapan media elekronik pada pembelajaran Bahasa Arab bagi siswa MTs Normal Islam disebabkan oleh adanya faktor inernal dan ekternal yang dihadap oleh pengajar dan siswa selama kegiatan belajar mengajar dilakukan dengan cara WFH, sehingga berpengaruh terhadap kelancaran pelaksanaan pembelajaran Bahasa Arab tersebut.

Adapun faktor internal yang menjadi kendala dalam pelaksanaan pembelajaran Bahasa Arab melalui media elektronik selama WFH diantaranya adalah pertama gaya belajar siswa yang beragam, kedua kemampuan kebahasaan siswa yang bervariasi, ketiga motivasi belajar siswa. Ketiga faktor tersebut merupakan dampak 
yang paling dominan dalam mempengaruhi perkembangan kecerdasan emosional mereka selama kehiatan belajar mengajar dilakukan di rumah, sedangkan selama ini mereka berada dilingkungan sekolah terbilang cukup lama dibandingkan waktu yang harus mereka habiskan di rumah dengan kegiatan yang lebih santai dan tidak ditekan dengan banyaknya tugas atau latihan-latihan. Sementara sejak diberlakukan sistem pendidikan melalui WFH mayoritas siswa merasa jenuh dan bosan dengan kegiatan belajar mengajar yang monoton, tanpa kehadiran sosok pengajar dan kawan-kawan yang biasanya hadir dikala sedang menerima ilmu pengetahuan.

Tanggap jawaban dari seluruh respondent tersebut dapat dilihat berdasarkan klasifikasi diagram terhadap tanggap para siswa selama proses kegiatan belajar mengajar yang dilakukan secara WFH khususnya terhadap bidang studi Bahasa Arab sebagaimana tergambar dalam diagram berikut ini

Suasana yang dirasakan siswa semala pelaksanaan KBM Bahasa Arab secara W

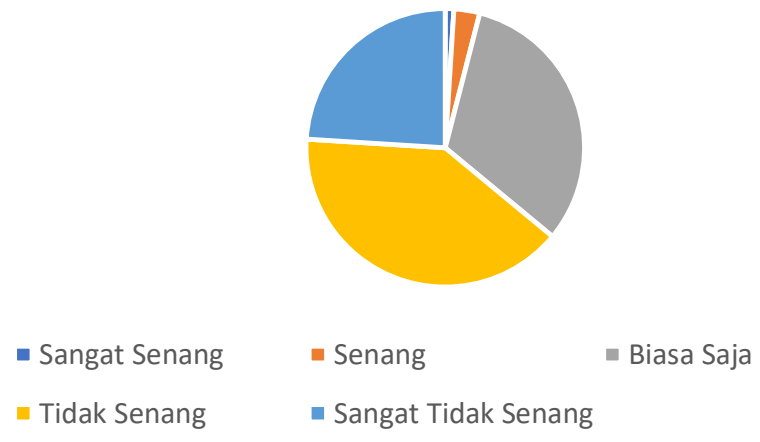

Jika melihat kondisi sebagaimana yang tergambar pada diagram diatas, maka mayoritas siswa lebih menyukai pelaksanaan kegiatan belajar mengajar Bahasa Arab yang dilakukan secara langsung di lingkungan sekolah, hal ini tidak terlepas dari tiga faktor yang mempengaruhi kondisi yang mereka alami selama kegiatan pendidikan harus dilakukan secara jarak jauh. Dimana rutinitas kehidupan sehari-hari mereka harus dibatasi bahkan interaksi sosial pun harus mulai dikurangi, hal yang demikanlah menjadi pengaruh negatif pada masa tumbuh kembang siswa khususnya bagi kesehatan mental mereka ${ }^{20}$. Dengan demikian mereka tidak akan memiliki motivasi belajar yang tidak baik, hal ini dialami oleh seluruh individu yang memiliki status sebagai siswa mulai dari tingkat dasar hingga perguruan tinggi.

Selain faktor internal yang menjadi kendala dalam penerapan media elektronik dalam pembelajaran Bahasa Arab bagi siswa MTs Normal Islam faktor eksternal juga merupakan kendala yang dirasakan oleh siswa, diantara faktor ekternal tersebut adalah pertama minimnya fasilitas, kedua lingkungan yang kurang mendukung, ketiga biaya pengeluaran untuk menunjang pendidikan, dan keempat waktu dan tenaga. Empat faktor eksternal ini menjadi faktor utama yang menghambat kegiatan pembelajaran Bahasa Arab.

Pertama minimnya fasilitas yang dimiliki siswa karena tidak semua individu memiliki fasilitas yang lengkap selama WFH, seperti komputer, laptop, printer, atau bahkan smartphone. Mayoritas siswa hanya memiliki salah satu jenis media elektornik saja, dan media yang paling banyak dimilik oleh siswa adalah media elektronik yang paling sering mereka gunakan dalam kehidupan sehari-hari yakni smartphone, akan tetapi memiliki hanya salah satu media elektronik tidak dapat memaksimalkan kegiatan pembelajaran Bahasa Arab. Sebab tidak semua smartphone memiliki kapasitas yang baik khususnya jika dimanfaatkan untuk pembelajaran Bahasa Arab dimana bahasa yang digunakan harus ditulis menggunakan huruf-huruf hijaiyah, dan tidak semua smartphone dapat mengakses secara maksimal aplikasi pembelajaran Bahasa Arab.

Kedua lingkungan yang kurang mendukung ini dimaksudkan tidak semua siswa mendapatkan bimbingan atau bantuan yang maksimal, sebab tidak semua orang tua siswa memiliki kemampuan yang baik dikala harus mendampingi siswa belajar Bahasa Arab, disamping itu tingkat hasil belajar pada Bahasa Arab saat ini memiliki standar yang

20 Wenjun Cao and others, 'The Psychological Impact of the COVID-19 Epidemic on College Students in China', Psychiatry Research, 287.March (2020), $1-5$ <https://doi.org/10.1016/j.psychres.2020.112934>. 
lebih tinggi berdasarkan perkembangan model kurikulum yang selalu mengalami membahruan berdasarkan kebijakan yang ditetapkan oleh kementerian pendidikan.

Ketiga biaya pengeluaran untuk menunjang pendidikan, jika selama ini biaya yang harus dikeluarkan oleh masing-masing orang tua atau wali siswa dalam setiap bulannya hanyalah membayar iuran SPP, uang saku siswa. Namun sejak seluruh kegiatan pendidikan berbasis WFH mayoritas orang tua atau wali siswa mengeluhkan masalah keuangan atau anggaran yang harus dikeluarkan lebih banyak dari biasanya. Biaya yang harus dikeluarkan untuk membayar paket jaringan internet agar dapat mengakses media elektonik yang digunakan selama pembelajaran Bahasa Arab berlangsung, bahkan biaya tagihan listrik juga menjadi semakin banyak karena media elektronik hanya dapat digunakan dengan tenaga listrik.

Keempat waktu dan tenaga merupakan ujung tombang dari ketiga faktor eksternal, karena ketiga faktor tersebut seluruhnya membutuhkan waktu yang lebih banyak dan tenaga yang ekstra, masing-masing orang tua atau wali siswa harus banyak meluangkan waktunya bukan hanya untuk keperluan pribadi saja melainkan mereka harus ikut serta mendampingi anak-anak mereka untuk melaksanakan kegiatan pendidikan di rumah, bahkan para orang tua atau wali siswa dituntun untuk dapat menggantikan peran para pengajar, sehingga terkadang tidak sedikit orang tua atau wali siswa merasa memiliki beban tersendiri selama kegiatan pendidikan ditiadakan dari lingkungan sekolah dan harus diganti dengan sistem pendidikan berbasis WFH.

\section{SIMPULAN}

Penerapan media elektronik dalam pembelajaran Bahasa Arab bagi siswa MTs Normal Islam Samarinda dilakukan secara masimal sejak diberlakukan kebijakan sosial distancing, sehingga berdampak pada sistem pembelajaran dan seluruh kegiatan pendidikan bagi para pengajar, siswa, serta orang tua atau wali siswa yang harus dilakukan secara WFH. Namun dalam implementasinya terdapat kendala yang menghambat kelancaran proses pembelajaran Bahasa Arab baik secara internal maupun eksternal yang dialami akibat kebijakan pendidikan selama wabah covid-19 melanda diseluruh lapisan kalangan masyarakat di muka bumi ini.

\section{DAFTAR PUSTAKA}

Abidin, Zainul, 'Penerapan Pemilihan Media Pembelajaran', Edcomtech: Jurnal Kajian Teknologi Pendidikan, 1.1 (2016), 9-20

Andriani, Asna, 'Urgensi Pembelajaran Bahasa Arab Dalam Pendidikan Islam', Ta'allum: Jurnal Pendidikan Islam, 3.1 (2015), $39-56$ <https://doi.org/10.21274/taalum.2015.3. $1.39-56>$

Budianto, Nanang, and Khuri'In Ratnasari, 'Memperkuar Pendidikan Islam Di Era (Four Point Zero/4.0)', Falasifah: Jurnal Studi Keislaman, 11.1 (2020), 62-78 <https://doi.org/https://doi.org/10.36835/ falasifa.v11i1.277>

Cao, Wenjun, Ziwei Fang, Guoqiang Hou, Mei Han, Xinrong Xu, Jiaxin Dong, and others, 'The Psychological Impact of the COVID-19 Epidemic on College Students in China', Psychiatry Research, 287.March (2020), 1-5 <https://doi.org/10.1016/j.psychres.2020. 112934>

Dewi, Wahyu Aji Fatma, 'Dampak Covid-19 Terhadap Implementasi Pembelajaran Daring MI', Edukatif: Jurnal Ilmu Pendidikan, $2.1 \quad$ (2020), 55-61 <https://doi.org/https://doi.org/10.31004/ edukatif.v2i1.89>

Fatkhurrohman, 'Sistem Pengajaran Bahasa Arab Di Indonesia Dan Problem Berbahasa Arab Secara Aktif', Lisanan Arabiya: Jurnal Pendidikan Bahasa Arab, I.1 (2017), 92-102

Fauzan, 'Menjaga Keragaman Ekonomi Rakyat Di Tengah Pandemi Covid-19', Pendidikan Multikultural, 4.1 (2020), 112-23

<https://doi.org/http://dx.doi.org/10.3347 4/multikultural.v4i1.6719>

Fauzan, Umar, and Luluk Humairo Pimada, 'ICT-Based Teaching of English at Madrasah Aliyah in Kalimantan', 
TARBIYA: Journal of Education in Muslim Society, 5.2 (2018), 193-211 $<$ https://doi.org/10.15408/tjems.v5i2.104 14>

Firman, and Sari Rahayu, 'Pembelajaran Online Di Tengah Pandemi Covid-19', Indonesian Journal of Educational Science (IJES), 2.2 (2020), 81-89 <https://doi.org/10.31605/ijes.v2i2.659>

Greenstone, Michael, and Vishan Nigam, 'Does Social Distancing Matter?', SSRN Electronic Journal, 2020 <https://doi.org/10.2139/ssrn.3561244>

Hafid, H.abd, 'Sumber Dan Media Pembelajaran', Jurnal Sulesana, 6.2 (2011), $69-78$ <https://doi.org/https://doi.org/10.24252/ .v6i2.1403>

Hafsah, Nandya RJ, Dedi Rohendi, and Purnawan Purnawan, 'Penerapan Media Pembelajaran Modul Elektronik Untuk Meningkatkan Hasil Belajar Siswa Pada Mata Pelajaran Teknologi Mekanik', Journal of Mechanical Engineering Education, 3.1 (2016), 106-12 <https://doi.org/10.17509/jmee.v3i1.320 $0>$

Iswanto, Rahmat, 'Pembelajaran Bahasa Arab Dengan Pemanfaatan Teknologi', Arabiyatuna: Jurnal Bahasa Arab, 1.2 (2017), 139 <https://doi.org/10.29240/jba.v1i2.286>

Khasanah, Dian Ratu Ayu Uswatun, Hascaryo Pramudibyanto, and Barokah Widuroyekti, 'Pendidikan Dalam Masa Pandemi Covid-19', Jurnal Sinestesia, 10.1 (2020), 41-48

Koderi, 'Pengembangan Modul Elektronik Berbasis SAVI Untuk Pembelajaran Bahasa Arab', Jurnal Teknologi Pendidikan, 19.3 (2017), 206-23 $<$ https://doi.org/https://doi.org/10.21009/ JTP1903.4>

Milles. Huberman, Analisis Data Kualitatif, (Jakarta: Universitas Indonesia Press, 1992), 16.

Maharaj, Savi, and Adam Kleczkowski, 'Controlling Epidemic Spread by Social Distancing: Do It Well or Not at All.', BMC Public Health, 12 (2012), 679 <https://doi.org/10.1186/1471-2458-12-
679>

Mahmudah, Siti, 'Media Pembelajaran Bahasa Arab', An Nabighoh Jurnal Pendidikan Dan Pembelajaran Bahasa $\begin{array}{lll}\text { Arab, } & 20.01 \quad \text { (2018), } & 129\end{array}$ $<$ https://doi.org/10.32332/annabighoh.v20i01.1131>

Pimada, Luluk Humairo, Imam Muttaqin, and Wildana Wargadinata, 'Arabic Learning Though the Ability of Reading and Writing Al-Qur'an in Tsanawiyah Madrasah Level Students in East Kalimantan', Taqdir: Jurnal Pendidikan Bahasa Dan Kebahasaan, 5.2 (2019), 117

<https://doi.org/https://doi.org/10.19109/ taqdir.v5i2>

Priyatmoko, S, 'Memperkuat Eksistensi Pendidikan Islam Di Era 4.0', Ta'lim: Jurnal Studi Pendidikan Islam, 1.2 (2018), 221-39 <https://doi.org/https://doi.org/10.29062/ ta'lim.v1i2.948>

Purwanto, Agus, Rudy Pramono, Maduki Asbari, Priyono Budi Santoso, Laksmi Mayesti Wijayanti, Choi Chi Hyun, and others, 'Studi Eksploratif Dampak Pandemi COVID-19 Terhadap Proses Pembelajaran Online Di Sekolah Dasar', Journal of Education, Psychology, and Counseling, $2.1 \quad$ (2020), 1-12 <https://www.researchgate.net/publicatio n/340661871_Studi_Eksploratif_Dampa k_Pandemi_COVID-

19_Terhadap_Proses_Pembelajaran_Onl ine_di_Sekolah_Dasar>

Rahmawati, Diah, 'PEMANFAATAN WORDERSHARE QUIZ CREATOR DALAM PEMBUATAN SOAL-SOAL BAHASA ARAB Arabi: Journal of Arabic Studies', Journal of Arabic Studies, $2.1 \quad$ (2017), 37-46 <https://doi.org/http://dx.doi.org/10.2486 5/ajas.v2i1.24>

Sa'adah, Nailis, 'Problematika Pembelajaran Nahwu Bagi Tingkat Pemula Menggunakan Arab Pegon', Lisanan Arabiya: Jurnal Pendidikan Bahasa Arab, $\quad 3.01 \quad$ (2019), 15-32 <https://doi.org/10.32699/liar.v3i01.995 $>$ 
Setyawan, Cahya Edi, and Khairul Anwar,

'Peran Bahasa Arab Dalam Pendidikan

Islam Sebagai Urgensitas Mengahadapi

Revolusi Industri 4.0', Jurnal Lahjah

Arabiah, 1.1 (2020), 14-29

Singh, Rajesh, and R. Adhikari, 'Age-

Structured Impact of Social Distancing on the COVID-19 Epidemic in India', 19 <http://arxiv.org/abs/2003.12055>

Subarto, 'Momentum Keluarga Mengembangkan Kemampuan Belajar Peserta Didik Di Tengah Wabah Pandemi Covid-19', Adalah: Buletin Hukum Dan Keadilan, 4.1 (2020), 13-18 <https://doi.org/10.15408/adalah.v4i1.15 383>

Syahid, Ahmad Habibi, 'Bahasa Arab Sebagai Bahasa Kedua (Kajian Teoretis Pemerolehan Bahasa Arab Pada Siswa Non-Native)', ARABIYAT: Jurnal Pendidikan Bahasa Arab Dan Kebahasaaraban, 2.1 (2015), 86-97 <https://doi.org/10.15408/a.v2i1.1797>

Wahyuni, Imela, 'Bahasa Arab Dalam Konteks Simbol Agama (Analisis Terhadap Tujuan Pembelajaran Pda Perguruan Tinggi)', Zawiyah: Jurnal Pemikiran Islam, 3.2 (2017), 79-92 <https://doi.org/http://dx.doi.org/10.3133 2/zjpi.v3i2.720>

Wekke, Ismail Suardi, 'Tradisi Pesantren Dalam Konstruksi Kurikulum Bahasa Arab Di Lembaga Pendidikan Minoritas Muslim Papua Barat', Karsa: The Journal of Social and Islamic Culture, $22.1 \quad$ (2015), 20-38 <https://doi.org/10.19105/karsa.v22i1.54 9>

Widyasari, Rully Rina, and M. Mukhibat, 'Repisisi Dan Reaktualisasi Pendidikan Madrasah Dalam Memperkuat Eksistensi Pendidikan Di Era 4.0', Edukasia: Jurnal Pendidikan Dan Pembelajaran, 1.1 (2020), 1-13

Wijaya, Ida Suryani, and Luluk Humairo Pimada, 'Ta'lim Al-Imla' Bi Al-Wasait Al-Muta'addodah Li Tarqiyati Maharah Al-Kitabah Fi Al-Lughah Al-'Arabiyah', Jurnal Al Bayan: Jurnal Jurusan Pendidikan Bahasa Arab, 11.2 (2019), 194-213 